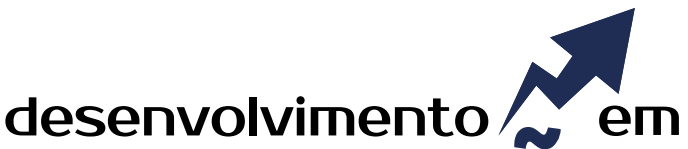 QUESTÂO
}

\section{Resíduos Gerados nas Favelas \\ Impactos sobre o Direito à Moradia Adequada, o Ambiente e a Sociedade}

http://dx.doi.org/10.21527/2237-6453.2020.50.325-342

Recebido em: 25/11/2018

Aceito em: 6/8/2019

\author{
Janaína Accordi Junkes, ${ }^{1}$ Alan do Nascimento Pedrosa, ${ }^{2}$ \\ Daniglayse Santos Vieira, ${ }^{3}$ Vivianny Kelly Galvão ${ }^{4}$
}

\begin{abstract}
RESUMO
Esta pesquisa propõe-se a identificar os problemas gerados pelo manejo inadequado de resíduos em uma favela pertencente à região do Polo Multissetorial de Maceió (AL). Pretende-se observar os reflexos desse manejo na saúde dos indivíduos que ali residem, sua relação com a bacia de drenagem de água pluvial e a rotina de atividades inerentes ao Polo. Para tanto, foram realizadas pesquisas de campo, aplicados questionários, realizadas entrevistas e registros fotográficos. A partir destes dados foi possível constatar que a comunidade em estudo, por ter seu esgoto interligado a uma bacia de drenagem, contribui diretamente para a geração de impactos que atingem questões relacionadas ao fluxo de águas pluviais, ao saneamento básico e, por sua vez, à saúde dos habitantes da região. A situação dos moradores atinge também o objetivo de desenvolvimento sustentável $n$. 6 da Agenda 2030 das Nações Unidas. É possível, por meio do parâmetro do direito à moradia adequada, entender a complexidade dos impactos de um sistema de saneamento básico deficiente sobre a gama de direitos humanos que o Estado deve proteger. Assim, este trabalho tem sua justificativa, dada a importância científica e social de dialogar sobre o planejamento para o manejo dos resíduos, tendo em vista que são geradas cerca de 183,5 mil toneladas de resíduos sólidos/dia, segundo dados de 2012 do Instituto de Pesquisa Econômica Aplicada, Ipea, bem como a um consumo de água que chega a 165,3 litros/habitante/ dia, os quais se tornarão esgoto. Logo, estudar os mecanismos de como lidar com estes resíduos é de extrema importância.
\end{abstract}

Palavras-chave: Favelas. Resíduos sólidos e líquidos. Saneamento. Doenças.

WASTE GENERATED IN THE FAVELAS:

IMPACTS ON THE RIGHT TO ADEQUATE HOUSING, THE ENVIRONMENT AND SOCIETY

\section{ABSTRACT}

This research proposes to identify the problems generated by the management of waste in a shanty town belonging to the region of the Multissectorial Pole of Maceió (AL). It's intended to observe the reflexes of this management in the health of the individuals who live there, its relation with the basin of drainage of rainwater and the routine of activities inherent to the Pole. For that, field surveys were carried out, questionnaires were applied, interviews and photographic records were carried out. Based on these data, it was possible to verify that the community in study, because its sewage interconnected to a drainage basin, directly contributes to the generation of impacts that reach issues related to the flow of rainwater, to basic sanitation and, in turn, to health of the inhabitants of the region. The situation of the residents affects too the Sustainable Development objective n. 6 of the United Nations Agenda 2030. It is possible, through the right to adequate housing parameter, to understand the complexity of the impacts of a poor sanitation system on the range of human rights that the state must protect. Thus, this work has its justification, given the scientific and social importance of discussing the planning for waste management, given that approximately 183.5 thousand tons of solid waste/day are generated, according to 2012 data from the Research Institute Applied Economics, IPEA, as well as a water consumption that reaches 165.3 liters/inhabitant/day, which will become liquid waste. Therefore, studying the mechanisms of how to deal with these wastes is of the utmost importance.

Keywords: Slum. Solid and liquid wastes. Sanitation. Diseases.

\footnotetext{
${ }^{1}$ Doutora em Ciência e Engenharia de Materiais pela Universidade Federal de Santa Catarina (UFSC). Professora do Centro Universitário Tiradentes (Unit). janajunkes@hotmail.com

${ }^{2}$ Mestre em Sociedade, Tecnologias e Políticas Públicas pelo Centro Universitário Tiradentes (Unit). Bolsista Capes. alan.eng.ambiental@ gmail.com

${ }^{3}$ Mestre em Sociedade, Tecnologias e Políticas Públicas pelo Centro Universitário Tiradentes (Unit). Graduada em Enfermagem e Obstetrícia pela Universidade Federal de Alagoas (Ufal). daniglayse.sv@hotmail.com

${ }^{4}$ Doutora em Ciências Jurídicas pela Universidade Federal da Paraíba (UFPB). Professora do Centro Universitário Tiradentes (Unit). viviannygalvao@hotmail.com
} 
O crescimento dos aglomerados subnormais, popularmente conhecidos como favelas, está historicamente ligado ao processo de urbanização acelerado no Brasil a partir das décadas de 60 e 70 (DE ASSIS LIBÂNIO, 2016). Com as mudanças demográficas geradas pelo intenso fluxo migratório rural-urbano, o crescimento desordenado das habitações se configurou num dos maiores reflexos destas mudanças. Esse crescimento, por sua vez, desencadeia em problemas ambientais por meio das modificações feitas pelo ser humano que geram a alteração da qualidade do ar, do solo e da água.

O fenômeno do êxodo rural, quando as pessoas, buscando uma vida melhor, superlotam as capitais, acaba por contribuir para a ineficiência de serviços básicos previstos pela Constituição, tais como a saúde e educação. E contribuem também para elevar indicadores socioeconômicos negativamente, como a taxa de desemprego e o índice de violência urbana. Segundo Sawaya, Albuquerque e Domene (2018), por exemplo, a violência provocada pelo sistema de tráfico de drogas é um dos maiores obstáculos para o insucesso dos serviços públicos de saúde nas favelas. Sistema este que é justificado pela falta de educação e oportunidade de trabalho ocasionado pelo excedente populacional.

Exemplos como este nos fazem compreender a dimensão dos efeitos desse fenômeno, contudo, nas políticas públicas, nas quais devemos encontrar as devidas soluções, é observado que há um discurso teórico da defesa ao meio ambiente que ao ser posto em prática é visto de modo contraditório na instituição dos programas de urbanização de favelas, pois estes nem sempre garantem o pleno direito à moradia ou alcançam a qualidade ambiental e urbanística adequada (DENALDI; FERRARA, 2018).

Esta ineficiência na efetivação das políticas públicas deve ser analisada por várias vertentes. A hipótese levantada por Denaldi e Ferrara (2018) é de que os avanços relacionados com o aprimoramento jurídico e institucional do planejamento urbano e ambiental ainda não desencadearam significativamente na prática operacional das políticas e programas, pois é preciso analisar isoladamente cada forma de apropriação do espaço natural e de surgimento do espaço de favela (DENALDI; FERRARA, 2018).

Outra vertente que se pode considerar é o da insuficiência da oferta de moradias novas pelo mercado e pelo setor público, em virtude dos mecanismos de financiamento habitacional e a demanda de terras. São limitações no planejamento do espaço urbano que culminarão em posteriores problemas ambientais (IPEA, 2016). Moreira (1999) ressalta, por sua vez, que o espaço urbano surge como consequência da relação que o homem tem com o espaço construído e a natureza e no instante em que surgem aglomerados populacionais e as atividades humanas se diversificam, essa relação produz mudanças no ambiente para adequação das necessidades do homem e para torná-lo apto a sua habitação e atividades. O fato é, no entanto, que, sendo a população destes aglomerados formada por indivíduos de baixa renda e com pouco estudo, estas mudanças tendem a gerar impactos negativos tanto ao ambiente quanto à saúde desta população.

Sim, é correto afirmar que a pobreza e a desigualdade são fatores fundamentais para o surgimento e agravamento da precariedade dos assentamentos humanos dentro dos espaços urbanizados, mas é importante observar também que os maus hábitos relacionados à disposição e manejo de resíduos sólidos urbanos nos aglomerados subnormais muitas vezes não se diferem dos de outros bairros da cidade, independentemente de classe social (SCHUELER; KZURE; RACCA, .2018). Este fator evidencia a necessidade 
da adoção de um modelo de gestão municipal que veja formas de criar e fiscalizar políticas de planejamento dos espaços de favelização, mas também de inserir a educação ambiental como uma atividade indispensável na consolidação e êxito das ações de gerenciamento dos resíduos sólidos, educando, fazendo despertar a consciência ambiental de modo que a população de interesse perceba a importância da real necessidade de conservar o ambiente em que vive (TAVARES, 2014).

Assim, tendo em vistas que as decisões que envolvem o gerenciamento de resíduos sólidos urbanos são fundamentalmente decisões sobre saúde pública e requerem, portanto, a integração entre políticas econômicas, sociais e ambientais (GOUVEIA, 2012). O objetivo desta pesquisa é caracterizar o problema do manejo inadequado de resíduos sólidos e líquidos, dentro de um cenário de expansão urbana populacional e territorial irregular, nas proximidades do Polo Multissetorial de Maceió, mais especificamente na Comunidade da Sombra dos Eucaliptos no bairro Tabuleiro dos Martins, como um estudo de caso deste amplo tema inerente à política ambiental. Foi analisado, portanto, como o descarte e despejo incorreto dos resíduos estão desencadeando problemas socioambientais e quais são estes, levando em conta o agravamento devido à ausência de assistência à saúde e à educação pela população que reside nesses aglomerados subnormais, as chamadas favelas.

A pesquisa de campo e aplicação de questionários foram as técnicas empregadas para a captação de dados, além de consultas aos dados obtidos pelas Secretarias Municipais de Infraestrutura (Seinfra) e também a Superintendência de Limpeza Urbana de Maceió (Slum).

\section{MÉTODOS E TÉCNICAS}

Dentro de uma metodologia qualitativa, este estudo teve seu embasamento a partir da realização de pesquisa de campo que incluiu entrevistas com moradores, a aplicação de questionários, registros fotográficos, percepção pessoal e pesquisas bibliográficas.

Com os dados coletados a partir da aplicação dos questionários foi construído um banco de dados, proporcionando a utilização desses dados para levantar um panorama do perfil dos entrevistados, e, por sua vez, dos moradores da comunidade em estudo. Gráficos foram gerados também com estes dados, que contribuíram para a compreensão da discussão proposta.

Em relação às entrevistas, foi aplicado um questionário contendo 15 perguntas fechadas a um público selecionado com o auxílio de um representante da Pastoral da Família, grupo religioso que faz ação social periódica com a comunidade. Desse modo, foi possível dividir os voluntários e as etapas da seguinte forma: 1익 - 5 entrevistados autodeclarados do sexo masculino e 20 dia -5 entrevistados autodeclarados do sexo feminino. Destas 10 entrevistas, 5 foram realizadas na parte alta da comunidade, mais urbanizada, e na semana seguinte foram realizadas outras 5 na parte baixa, parte mais carente em termos gerais, como mostra a Tabela 1. 
Tabela 1 - Dados básicos dos moradores da favela

\begin{tabular}{|l|c|c|c|}
\hline \multicolumn{4}{|c|}{ PERFIL DOS ENTREVISTADOS } \\
\hline \multirow{4}{*}{ Sexo } & Escolaridade & $\begin{array}{c}\text { Tempo de moradia } \\
\text { (Anos) }\end{array}$ & Local \\
\hline \multirow{4}{*}{ Feminino } & F. C. & 2 & PB \\
\cline { 2 - 4 } & F. I. & 12 & PB \\
\cline { 2 - 4 } & Médio I. & 13 & PB \\
\cline { 2 - 4 } & F. I. & 30 & PA \\
\cline { 2 - 4 } & F. I. & 20 & PA \\
\hline \multirow{3}{*}{ Masculino } & F. I. & 20 & PB \\
\cline { 2 - 4 } & F. C. & 10 & PB \\
\cline { 2 - 4 } & F. C. & 5 & PA \\
\cline { 2 - 4 } & Médio I. & 1 & PA \\
\cline { 2 - 4 } & F. I. & 38 & PA \\
\hline
\end{tabular}

*PA - Parte alta, PB - Parte baixa, FC - Fundamental completo, FI - Fundamental incompleto C, MC - Médio completo, $\mathrm{MI}$ - Médio incompleto.

\section{Fonte: Os autores.}

A Tabela 1 apresenta a estrutura do processo amostral dos entrevistados. É observado então que as unidades amostrais são indivíduos de domicílios diferentes compondo um desenho amostral separado por local, ou seja, uma amostra da parte alta e uma amostra da parte baixa.

Complementando, também foram entrevistados em formato de gravação em áudio/vídeo três moradores da comunidade, identificados pelos próprios moradores como os residentes mais antigos do local.

Os registros fotográficos foram realizados contemplando as etapas a serem discutidas: o trato e o depósito dos resíduos sólidos, as condições do esgotamento doméstico, as condições de drenagem de águas pluviais e os impactos adversos (contaminação de corredor de água pluvial, tubulações danificadas, esgoto a céu aberto, etc.) encontrados pelas condições dos quesitos tratados anteriormente.

\section{PERFIL DA COMUNIDADE E PRINCIPAIS CARACTERÍSTICAS DA REGIÃO DE ESTUDO}

A comunidade de estudo é vulgarmente conhecida como Favela da Coca-Cola, por estar inserida no Polo Multissetorial Governador Luiz Cavalcante, antigo polo industrial no bairro do Tabuleiro dos Martins, na cidade de Maceió-AL, onde se localizava uma distribuidora da empresa Coca-Cola. Essa região também é conhecida como Comunidade Rainha da Paz, segundo relatos da Pastoral da Criança, nome advindo das atividades religiosas da Paróquia de Nossa Senhora do Perpétuo Socorro, do conjunto Cleto Marques Luz, também no Tabuleiro dos Martins. A Paróquia está presente na comunidade e presta assistência semanal para as gestantes e mulheres com crianças até os 6 anos de idade, no entanto é pelo nome de Comunidade da Sombra dos Eucaliptos que a maioria dos habitantes identifica sua residência nessa região. Segundo relatos dos moradores mais antigo da comunidade, com 38 anos de habitação, este nome surgiu por que os aglomerados subnormais foram inseridos em uma área verde, que por sua vez possuía 
muitas árvores de eucalipto. Com o passar dos anos e a ampliação da favela, essas árvores foram extintas desse local, que conforme mostra a Figura 1, hoje possui pouco mais de $28 \mathrm{~m}^{2}$, mantendo uma distância aproximada de 162 metros da bacia de água pluvial.

Figura 1 - Vista superior da área de estudo e seu entorno

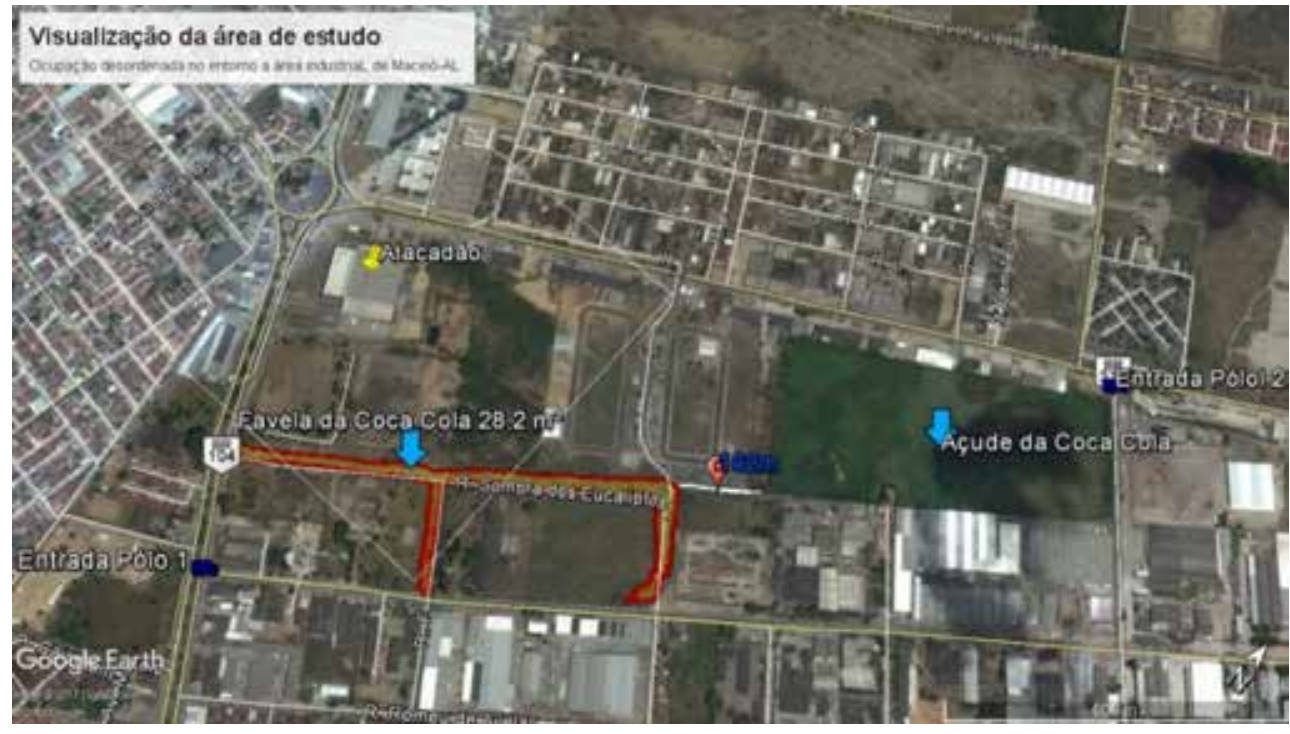

Fonte: Google Earth 2017 (imagem alterada pelos autores).

A comunidade da Sombra dos Eucaliptos possui atualmente cerca de 300 habitações entre casas e barracos, e o número de habitantes, segundo dados da Pastoral da Criança, é de 970 pessoas. Destas, cerca de 170 são crianças de até 12 anos. A Pastoral da Criança possui cadastradas 70 crianças no projeto para dar assistência àquelas com idade igual ou inferior aos 6 anos.

Dividida em dois espaços, na parte alta da favela, a mais antiga, encontram-se as residências caracterizadas por sua estrutura de alvenaria, com acesso à energia elétrica e água encanada, além de que muitas das moradias possuem fossas e as que não possuem, ao menos têm seus resíduos canalizados. Na parte baixa encontram-se residências feitas de forma artesanal, de materiais que vão desde papelões, placas de metal somados também à alvenaria.

\section{Aglomerados Subnormais e o Manejo dos Resíduos Sólidos e Líquidos}

Considera-se como resíduo sólido todo e qualquer material, substância, objeto ou bem descartado proveniente de atividades antrópicas e cuja destinação final se procede, se propõe a proceder ou se está obrigado a proceder, nos estados sólido ou semissólido, o que inclui gases contidos em recipientes e líquidos cujas particularidades tornem inviável o seu lançamento na rede pública de esgotos ou em corpos d'água, ou exijam para isso soluções técnicas ou economicamente viáveis em razão da melhor tecnologia disponível (FRANCA et al., 2013). Estes resíduos podem ser classificados como domésticos, quando originários de atividades domésticas urbanas; ou resíduos sólidos públicos, quando originários da varrição, limpeza de logradouros e vias públicas e outros serviços de limpeza urbana. Juntos dão origem aos chamados resíduos sólidos urbanos (RSU) (BRASIL, 2010). 
Os resíduos sólidos, ou simplesmente lixo, como são vulgarmente chamados, são abordados em diferentes políticas públicas brasileiras, como a Política Nacional de Saneamento Básico (Lei no 11.445/2007), na qual o plano municipal de resíduos sólidos deve integrar o plano municipal de saneamento e na Política Nacional de Resíduos Sólidos (PNRS) - Lei no 12.305/2010 (NASCIMENTO et al., 2015). Entre outros aspectos, a PNRS obriga os municípios a elaborarem um Plano Municipal de Gerenciamento Integrado de Resíduos Sólidos (PMGIRS), o que resultará na adoção de soluções que minimizem ou ponham fim aos efeitos negativos para a saúde pública e para o meio ambiente em cada fase do "ciclo de vida" dos produtos.

No cenário urbano como o da cidade de Maceió é comum encontrar habitações irregulares. São aglomerados ou favelas, em sua maioria carentes de serviços públicos essenciais (abastecimento de água, esgotamento sanitário, coleta de lixo e fornecimento de energia elétrica) os quais estão ligados à falta de regularização das habitações, que normalmente ocupam ilegalmente terra pública ou particular ou são habitações que possuem urbanização fora dos padrões vigentes, bem como vias de circulação estreitas e de alinhamento irregular, lotes de tamanhos e formas desiguais e construções não regularizadas por órgãos públicos (IBGE, 2010). Assim, as favelas de Maceió seguem este mesmo perfil.

Muito disso deve-se ao fato de que os mecanismos formais de acesso à terra e à moradia, seja pela via do mercado, seja pela via das políticas públicas, sempre foram insuficientes, atendendo, quando muito, apenas parte das necessidades reais da população (CARDOSO, 2016). Este cenário implicou a multiplicação das favelas que, em sua maioria, são compostas por habitações construídas pelos próprios moradores. Ainda segundo Cardoso:

O acesso à habitação só se viabilizou através de processos de ocupação de terras ociosas e da autoconstrução da moradia, gerando assentamentos insalubres, frequentemente ocupando áreas de risco e com a sua segurança física comprometida pela ausência de técnicas e de materiais adequados para a construção (2016, p. 29).

A autoconstrução surge como uma prática bastante comum no Brasil a partir da década de 80 . Esta prática é impulsionada pela necessidade da casa própria de famílias de baixa renda, sobretudo de famílias recém-formadas que desejam sair do aluguel. São moradias caracterizadas pela utilização de material de reuso (sobras de outras construções), materiais de baixo custo e/ou artesanais (madeiras de resto de móveis, placas de metal, etc.) e realizadas por pessoas sem capacitação, fora dos padrões da construção civil (BALTHAZAR, 2012).

Na capital de Alagoas este cenário é mais comum na região periférica, contudo, é nessa região que se encontra a matriz industrial da capital do Estado. Nesta região o uso e ocupação do solo são conduzidos pelo crescimento da área industrial e pela ocupação irregular no entorno. Logo, problemas ambientais causados pelo uso do solo, como a impermeabilização que bloqueia a drenagem da água, são fatores que precisam ser observados. 
Dentro da área de estudo têm-se as avenidas Governador Luís Cavalcanti, principal via do Polo Multissetorial, e a Menino Marcelo, a rua Sombra dos Eucaliptos e a estrada da Codeal, que cortam a favela. Como a região tem como fonte de escoamento de água pluvial uma bacia de drenagem, toda a área no entorno da bacia é área de influência às condições de funcionamento desta.

A fragilidade de seu funcionamento pode gerar problemas de escoamento ou até de transbordamento, gerando alagamentos nas vias e até na Comunidade da Sombra dos Eucaliptos. Alagamentos ou inundações são o acúmulo momentâneo de águas em determinados locais por deficiência no sistema de drenagem e enxurradas (LICCO; DOWEL, 2015). Esta situação pode ser ocasionada ou agravada principalmente pelo descarte incorreto de resíduos que prejudicam o escoamento da água/esgoto ou pela ligação clandestina de esgoto, aumentando a vazão de líquido para a bacia.

Os resíduos sólidos gerados no local, domésticos ou industriais, quando descartados nas ruas e terrenos baldios, diminuem a capacidade de infiltração no solo. A bacia de drenagem de águas pluviais do polo, pela falta de manutenção, apresenta um vasto crescimento vegetativo, importante para a evapotranspiração, mas que reduz sua capacidade de disponibilização hídrica.

Esta bacia, somada às dos conjuntos Eustáquio Gomes de Melo, Graciliano Ramos e Salvador Lyra, formam um complexo de bacias que tem por objetivo drenar a água da chuva da parte alta da cidade de Maceió, evitando alagamentos que prejudiquem os moradores e trabalhadores da região, bem como os estabelecimentos comerciais e órgãos públicos instalados naquela região (BISPO; LEVINO, 2011).

\section{Diagnóstico da Coleta dos Resíduos na Comunidade}

Conforme a Superintendência de Limpeza Urbana de Maceió (Slum), a coleta dos resíduos sólidos pelo caminhão da prefeitura é realizada semanalmente às terças, quintas e sábados no período noturno. Além da coleta normal, uma equipe realiza limpeza semanal de um ponto de lixo próximos à antiga Coca-Cola, segundo afirma a Assessoria de Comunicação (Ascom) da Slum, contudo não há cestos de lixo, nem quaisquer sinalizações que identifiquem um local padrão de descarte. Somente há espaços, caracterizados pela presença constante de resíduos, como os locais habitualmente utilizados como depósito do lixo doméstico. Do mesmo modo, por ser uma área industrial sem locais regulares de depósito de lixo, frequentemente pessoas não residentes utilizam o mesmo espaço para depósito de seus resíduos, que podem ser domésticos ou industriais.

A coleta seletiva, que é o recolhimento de resíduos sólidos previamente segregados conforme sua constituição ou composição (Artigo 3ำ V), como consta na Política Nacional de Resíduos Sólidos (PNRS), Lei no 12.305, de 2 de agosto de 2010, somente é realizada dentro de algumas distribuidoras e indústrias do Polo. Na comunidade da Sombra dos Eucaliptos alguns moradores, de forma autônoma, separam os resíduos a fim de comercializá-los para garantir uma renda extra.

Em geral são separados: papelões, recipientes plásticos e metais materiais que facilmente encontram compradores, por serem os que são mais comercializados, sobretudo pelas cooperativas. 


\section{Interface Meio Ambiente e Saúde: reflexo no processo saúde-doença}

As interações humanas com seu ambiente natural são complexas, e vários comportamentos são identificados à medida que essas relações ocorrem, sendo estas individuais e coletivas para com o entorno em que vivem (SILVA; SAMMARCO, 2015).

Foi a partir da 3a Conferência Internacional sobre Promoção da Saúde, em Sundsvall, na Suécia, em 1991, que a questão foi demarcada, do ponto de vista da interdependência entre saúde e ambiente em todos os seus aspectos, não somente físico, mas também social, econômico, político e cultural (BUSS, 2000).

No Brasil, o conceito de saúde, entendido como um estado de completo bem-estar físico, mental e social, não se restringe ao problema sanitário ou à prevalência de doenças. Hoje, além das ações de prevenção e assistência, considera-se cada vez mais importante atuar sobre os fatores determinantes da saúde. É este o propósito da promoção da saúde, que constitui o elemento principal das propostas da Organização Mundial da Saúde (OMS) e da Organização Pan-Americana de Saúde (Opas).

Logo, essa relação entre a tríade ambiente, indivíduo e saúde tem sido bastante estudada, procurando assim avaliar o impacto de condições ambientais adversas sobre a saúde.

A criação de ambientes favoráveis à saúde implica reconhecer a complexidade das sociedades e as relações de interdependência entre diversos setores, que perpassam a proteção do meio ambiente e o acompanhamento do impacto que as mudanças no meio ambiente causam sobre a saúde. Esta percepção passou a ter maior destaque na agenda da saúde (BUSS, 2000).

O ser humano não está isolado do meio ambiente, mas é parte integrante deste e sua saúde depende exclusivamente dessa relação direta. Um dos fatores fundamentais dentro desta relação é referente ao saneamento. A preocupação com este fator, ao longo do tempo, esteve quase sempre relacionada à transmissão de doenças e ao consequente aumento na produção de resíduos, bem como no descarte incorreto destes no meio ambiente.

Segundo a Organização Mundial da Saúde (OMS), saneamento é o controle de todos os fatores do meio físico do homem, que exercem ou podem exercer efeitos nocivos sobre o bem-estar físico, mental e social. De outra forma, pode-se afirmar que saneamento caracteriza o conjunto de ações socioeconômicas que têm por objetivo alcançar salubridade ambiental. Assim, entende-se como salubridade ambiental o estado de higidez (estado de saúde normal) em que vive a população urbana e rural no que se refere a sua capacidade de inibir, prevenir ou impedir a ocorrência de endemias ou epidemias veiculadas pelo meio ambiente (GUIMARÃES; CARVALHO; SILVA, .2007).

Lima (2014) ressalta que com uma maior magnitude, o ambiente passou a ser alterado de forma contínua, interferindo nas interações sociedade/meio ambiente/ agente/vetor. A tríade epidemiológica - para alguns, tríade ecológica das doenças - é composta por hospedeiro, agente e meio ambiente. O "desequilíbrio" desses "sistemas" leva ao surgimento e/ou aumento de casos de doenças, com um quarto elemento podendo estar envolvido no processo: os vetores (transmissores de doenças). 
No âmbito da vigilância em saúde que integra as práticas coletivas e individuais em diferentes dimensões das necessidades de saúde, incluindo, além do controle de riscos e danos, os determinantes ecossociais, podemos citar a vigilância epidemiológica, vigilância sanitária e a vigilância ambiental como instrumentos indispensáveis para o campo do saber e práticas da saúde pública.

Uma das doenças mais comuns em comunidades como esta da pesquisa é a dengue. "Aqui na comunidade a grande maioria das pessoas já teve a dengue". A dengue é uma doença infecciosa febril aguda, que pode ser benigna ou grave. É considerada um problema de saúde pública em todo o mundo, especialmente nos países tropicais, cujas condições socioambientais favorecem o desenvolvimento e a proliferação de seu principal vetor, o mosquito Aedes aegypti (BARRETO; TEIXEIRA, 2008).

Clinicamente, as manifestações variam de uma síndrome viral (febre alta, cefaleia, dores no corpo) inespecífica e benigna, até um quadro grave e fatal de doença hemorrágica com choque (febre alta, fenômenos hemorrágicos).

O que se observa atualmente no processo saúde-doença é a separação prática entre o meio ambiente e a saúde humana, com os profissionais de saúde e as políticas públicas, em geral, se limitando principalmente ao tratamento e aos cuidados dos doentes, ficando a prevenção em segundo plano. São necessárias, portanto, abordagens e atitudes para a promoção de saúde, qualidade de vida e prevenção de enfermidades associadas ao meio ambiente por parte dos profissionais da saúde.

\section{DIREITO À MORADIA ADEQUADA E A AGENDA 2030}

Os Objetivos de Desenvolvimento Sustentável (ODSs) e a Agenda 2030 têm sido amplamente divulgados no Brasil. Em 5 de junho de 2018 o governo de Alagoas promoveu em parceria com o Programa das Nações Unidas para Assentamentos Humanos (ONU-Habitat) o evento "Dia da ONU: Diálogos sobre desenvolvimento urbano, social e econômico". Este encontro foi impulsionado pelo Decreto Presidencial no 9.295, de 28 de fevereiro de 2018, que criou o Prêmio ODS Brasil. A premiação deve ser concedida a cada dois anos, até 2030, e vai reconhecer as boas práticas em quatro categorias distintas: Governos; Organizações com Fins Lucrativos; Organizações sem Fins Lucrativos e Instituições de Ensino, Pesquisa e Extensão. Ainda que seja uma agenda em fase inicial, revela-se um incentivo interessante para angariar a colaboração dos gestores públicos em favor da agenda "onusiana" dos ODSs.

A partir da linguagem dos direitos humanos, tendo como pressuposto a ideia de unicidade dessa categoria, ou seja, a ideia de que a violação de um direito humano acarreta a violação de tantos outros, é possível destacar o direito humano à moradia adequada. No caso pesquisado, o ODS cuja violação ficou mais evidente foi o Objetivo n. 6 (Assegurar a disponibilidade e gestão sustentável da água e saneamento para todos). Segundo as Nações Unidas, em 2015, 2,5 bilhões de pessoas ainda não tinham acesso a serviços de saneamento básico, como banheiros ou latrinas. Como decorrência dessa situação, a ONU alerta que diariamente uma média de 5 mil crianças morrem de doenças evitáveis relacionadas à água e saneamento (ONU, 2018c). 
A "tradução" dos fatos constatados na pesquisa de campo para a linguagem dos direitos humanos é útil sob a perspectiva da atual judicialização dos direitos sociais diante da inação do Estado. O exercício da cidadania passa pelo (re)conhecimento dos direitos e deveres. Ainda que a comunidade do Polo perceba a omissão do Estado, o alcance dos conteúdos dos direitos humanos e os mecanismos existentes para realizá-los são desconhecidos pela população. Por isso, é relevante destrinchar os aspectos do direito à moradia adequada (right to adequate housing) e verificar como esse direito é percebido pelo Judiciário brasileiro.

Segundo os Comentários Gerais n. 4 (1991), sobre o direito à moradia adequada, e o n. 7 (1997), sobre eviç̧ão forçada elaborados pelo Comitê de Direitos Econômicos, Sociais e Culturais, o direito à moradia adequada possui traços das liberdades públicas (proteção contra evicção forçada e destruição arbitrária; direito de ser livre de interferências arbitrárias em sua casa; privacidade e família; direito de escolher a residência, de determinar onde viver e liberdade de movimento), bem como titularidades de segurança da posse; restituição de casas, terras e propriedades; acesso igual e não discriminatório à moradia adequada; participação nas tomadas de decisão relacionadas à habitação nos níveis nacional e comunitário.

A adequação da moradia deve ser analisada sob os aspectos da segurança da posse, da disponibilidade de serviços, da acessibilidade, da habitabilidade e da localização. Pela soma desses aspectos é possível verificar o grau de adequação da moradia. Na pesquisa de campo a ausência de saneamento básico toca as recomendações acerca da disponibilidade de serviços, materiais, instalações e infraestrutura. Em outras palavras, segundo o Comitê, a moradia não é adequada se seus ocupantes não tiverem água potável, saneamento adequado, energia para cozinhar, aquecimento, iluminação, armazenamento de alimentos ou descarte de lixo.

De acordo com o registro de depósitos de tratados das Nações Unidas, o Brasil está vinculado ao Pidesc desde 24 de janeiro de 1992, mas ainda não é signatário dos Protocolo Facultativo ao Pidesc. Isto significa que o Brasil não autorizou o Comitê a receber denúncias individuais para instituição das normas do Pacto (ONU, 2018a). No último relatório apresentado pelo Brasil (E/C.12/BRA/CO/2 de 12 de junho de 2009), o Comitê apontou entre os pontos positivos na concretização do Pacto Internacional de Direitos Civis e Políticos (Pidesc):

(a) O Sistema Nacional de Habitação de Interesse Social (SNHIS), cuja tarefa principal é urbanizar as favelas, construir casas e melhorar as condições de moradia dos grupos de baixa renda;

(b) O Fundo Nacional de Habitação de Interesse Social, juntamente com o seu Conselho Gestor, concebido para centralizar e gerir recursos orçamentais para programas no âmbito do SNHIS.

O Comitê observou com preocupação o fato de mais de 6 milhões de pessoas ainda viverem em assentamentos urbanos precários no Brasil. Segundo o Comitê, o grande número de pessoas desabrigadas e os fluxos significativos de migração para áreas urbanas pioraram a situação da falta de moradias. O Comitê estava ainda preocupado com a 
ausência de medidas adequadas para proporcionar habitação social a famílias de baixa renda e a indivíduos e grupos desfavorecidos e marginalizados. Diante disso, o órgão internacional recomendou que:

[...] o Estado-Parte adote medidas adicionais para lidar com o problema dos sem-teto, assegure acesso adequado à moradia para famílias de baixa renda, indivíduos e grupos desfavorecidos e marginalizados e melhore as instalações de água e saneamento das unidades habitacionais existentes (ONU, 2018b).

Deste modo, no que se refere à moradia adequada, o Brasil ainda possui um longo caminho a percorrer. $\mathrm{O}$ caso das famílias do Polo Multissetorial está inserido em um problema de dimensão nacional. A afirmação de que todos têm direito a um padrão de vida adequado para si e sua família, incluindo alimentação adequada, roupas e moradia (artigo 11, Pidesc), ainda significa uma realidade distante dos moradores do Polo.

Voltando o olhar para o principal órgão do Judiciário brasileiro, a pesquisa de jurisprudência confirma uma hipótese deste trabalho, a judicialização do direito à moradia adequada no campo dos direitos sociais ainda não foi encampada pelos advogados públicos e privados, ao menos não na mesma dimensão do problema. Ao usar os descritores "moradia adequada Pidesc" em pesquisa de jurisprudência no Supremo Tribunal Federal foi encontrada uma decisão monocrática. A Medida Cautelar em Mandado de Segurança (MS 33069 MC/DF) de relatoria do ministro Gilmar Mendes, julgada em 30 de março de 2015, trata de um pedido ajuizado por Pedro Zeferino do Nascimentos e outros contra o Decreto de 13 de março de 2014, expedido pela Presidência da República, que declarou de interesse social - para fins de assentamento de indígenas - os imóveis situados no município de Rodelas, Estado da Bahia.

\section{DISCUSSÃO DOS RESULTADOS}

Na observância da comunidade da Sombra dos Eucaliptos foi pautado o estudo a partir de quatro perspectivas. Inicialmente o estudo se deu pela análise do manejo de resíduos sólidos dentro e fora da comunidade, Figura 2 . Posteriormente foi analisado o sistema de esgotamento doméstico e as redes de canalização. Em seguida foi observada a bacia de drenagem e por fim foram levantados os reflexos da relação entre o ambiente e a saúde.

Figura 2 - Relato dos moradores quanto ao manejo de seus resíduos

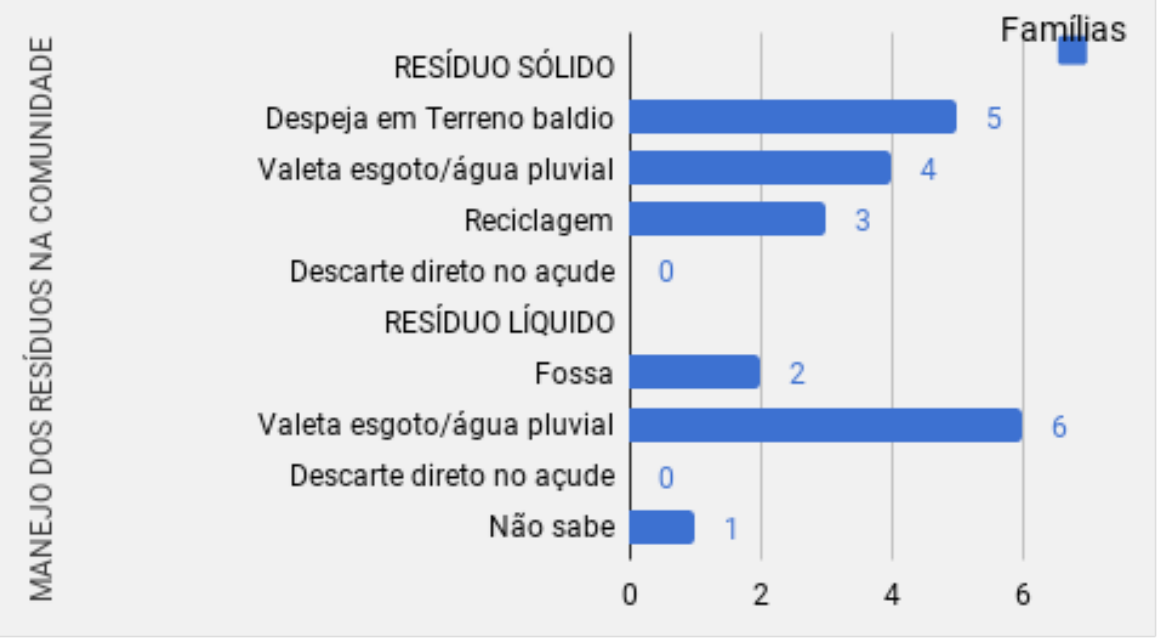

Fonte: Os autores. 
Em relação ao manejo dos resíduos os resultados revelam que embora haja coleta periódica promovida pela prefeitura e que alguns moradores ainda trabalhem com a reciclagem como forma de aumentar a renda familiar, a maioria dos habitantes, seja da parte alta ou baixa, faz o descarte do resíduo diretamente na valeta de esgoto e/ou em terreno baldio, o qual se transforma em depósito de lixo.

Também no terreno que fica na entrada lateral da comunidade surgiu este depósito de lixo. Um cenário insalubre criado não somente pelos habitantes da comunidade, mas também por empresas, possivelmente do próprio Polo, conforme Figura 3 , que descartam seus resíduos no local. São resíduos industriais, de construção civil, de poda ou outros, que assim como quaisquer resíduos sólidos urbanos no Brasil, deveriam ser diretamente encaminhados a aterros sanitários, e na sua ausência para um aterro controlado ou um lixão, que embora também seja impactante negativamente ao meio ambiente e à sociedade, é um depósito distante do centro urbano e que tem como objetivo abrigar esses materiais (JACOBI; BESEN, 2011).

Figura 3 - Depósitos de lixo na entrada da favela

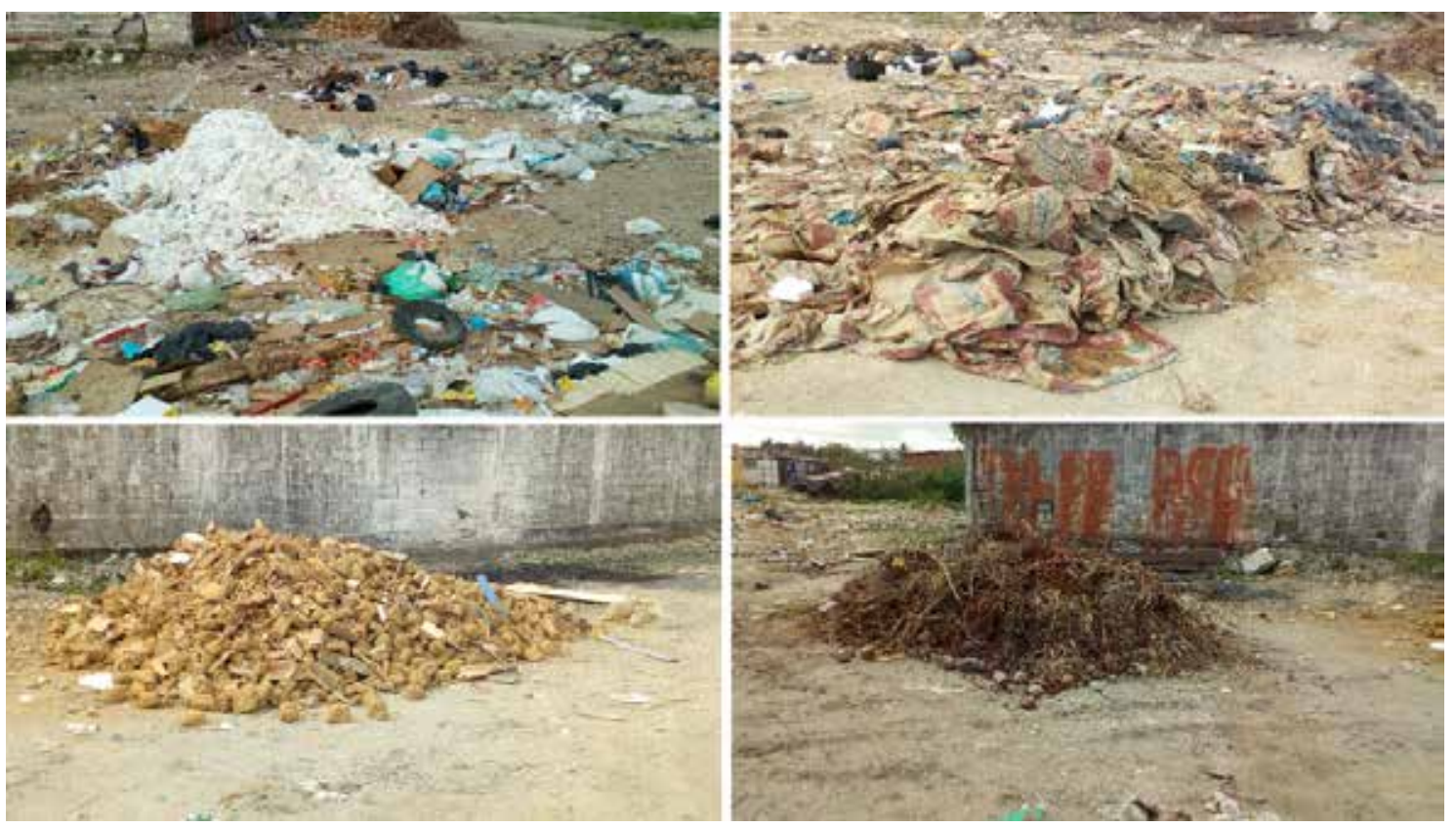

Fonte: Os autores.

Em relação ao esgotamento doméstico, observou-se duas realidades: enquanto boa parte dos moradores da parte alta (mais antiga) possuem fossas, a maioria dos moradores da parte baixa tem seus resíduos despejados no fundo do quintal (Figura 4 ), onde corre um esgoto a céu aberto que deságua na valeta de água pluvial. 
Figura 4 - Esgoto a céu aberto nos fundos da casa de um morador da comunidade

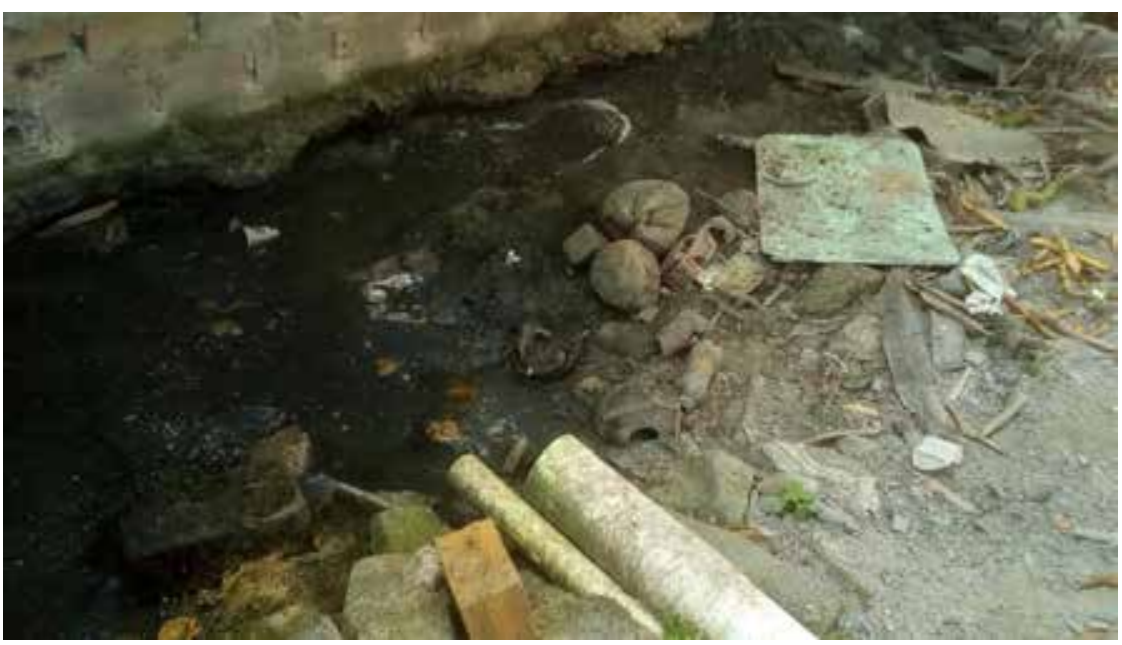

Fonte: Os autores.

As fossas, existentes em algumas residências, também revelam-se um fator negativo, pois nada mais são do que buracos que armazenam esgoto. A fossa séptica é um sistema confiável em que o esgoto é depositado em um poço, podendo ser feito de diversos materiais, em que a parte líquida é absorvida pelo solo e a sólida é removida mecanicamente, no entanto as únicas fossas encontradas na comunidade são as que são consideradas como fossas negras. O método da fossa negra constitui-se fundamentalmente na abertura de um buraco no solo, podendo ser coberto ou não, para onde são direcionados os dejetos e a água. Como não há camada protetora nem mecanismo de remoção, o conteúdo acaba por infiltrar e se dissipar, contaminando o solo e possivelmente o lençol freático (OLIVEIRA JÚNIOR, 2013). Esse método é uma forma primitiva de saneamento desenvolvida pelo homem para afastar de si os contaminantes oriundos dos mais diversos dejetos, evitando o lançamento em rios, lagos ou mesmo diretamente na superfície do solo. É um método bastante comum, não somente em aglomerados subnormais, mas em diversas áreas habitacionais carentes de saneamento básico (ARRUDA; LIMA; SCALIZE, $t$ al.2016). Essa prática ameaça a qualidade da água do lençol freático. Além disso, parte do esgoto que é escoado superficialmente por tubulações e canalizações passa pelas portas das casas e segundo relatos dos moradores, no inverno há uma elevação na vazão do esgoto, provocando odores, alagamentos temporários e favorecendo o aumento do aparecimento de vetores de doenças, tais como ratos, baratas e escorpiões.

No que se refere ao escoamento da água pluvial, tem-se que a bacia de drenagem seja a destinação final, funcionando como um facilitador do ciclo hidrológico. Nela parte da água infiltra, abastecendo o lençol freático e boa parte evapora, formando as nuvens, todavia, assim como as demais áreas da capital de Alagoas, a periferia sofre pela falta de saneamento básico. Observa-se que onde teve um planejamento para água pluvial não houve planejamento para o esgoto, logo, todo o esgoto gerado nas favelas e em seu entorno é direcionado para a valeta que deságua no açude. Esta prática torna-se ainda mais grave em períodos chuvosos, quando a elevada vazão chega a transbordar a bacia que não foi projetada para receber esgoto, inundando as vias e prejudicando o tráfego de veículos dentro e no entorno ao Polo Multissetorial. 
A Figura 5 mostra a valeta de esgoto, a qual foi projetada somente para fluxo de água de chuva, mas que recebe grande parte do resíduo líquido da favela e de conjuntos vizinhos ao Polo.

Figura 5 - Valeta de canalização de água pluvial

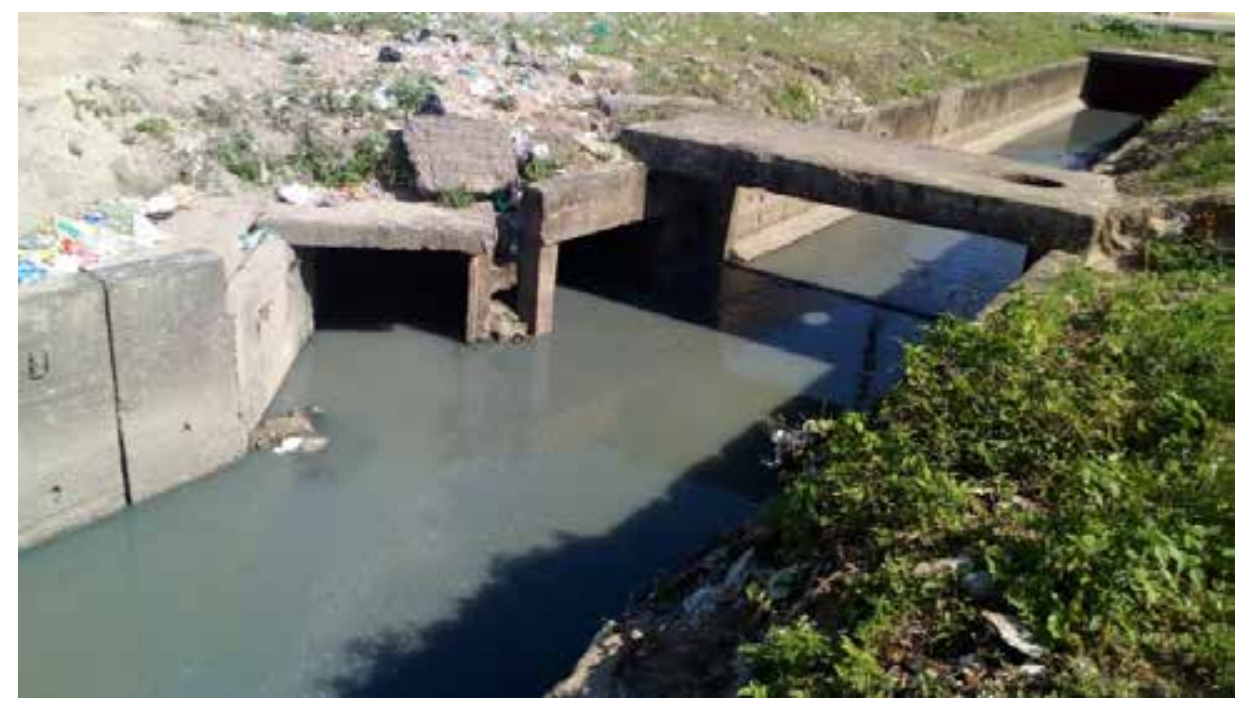

Fonte: Os autores.

Por meio da aplicação do questionário desenvolvido foi possível perceber que os problemas ambientais contribuem de forma considerável para o aparecimento de doenças. Entre as dez famílias entrevistadas, todas relataram que ao menos uma das infecções já acometeu moradores relacionada com o saneamento (água, excretas, lixo). Foram relatadas durante as entrevistas: hepatite $A$, giardíase (doenças do tipo fecal-oral-transmissão hídrica ou relacionada com a higiene), doenças infecciosas da pele (doenças do tipo não fecal-oral-relacionadas com a higiene), leptospirose e esquistossomose (doenças transmitidas por água contaminada), dengue, zika, chikungunya (doenças transmitidas por inseto vetor) e a leptospirose (doenças relacionadas com vetores roedores).

"Meu vizinho morreu dessa doença, começou a ficar amarelo, barriga grande, disseram que foi por conta do xixi do rato, aqui tem muito rato"

Tal relato condiz com a poluição visual observada durante a caminhada na comunidade, onde a presença de vetores como moscas, mosquitos, baratas, ratos e outros animais ocupam espaço neste nicho.

"Às vezes, à noite estamos sentados na porta conversando e a gente vê os ratos passando, tem uns que são tão grandes que pensamos até que se trata de outro animal"; "O cheiro da pocilga é horrível, mais não podemos nem reclamar, por conta dela tem muitas moscas, baratas e isso pode trazer doenças para gente, né". Estes relatos indicam que a situação no local é grave em relação à infestação de ratos e insetos.

Além de animais como galinhas, gatos e cachorros, existe dentro da comunidade uma criação de suínos, tanto para consumo próprio como para comercialização. As populações animais podem ser portadoras de doenças e representam um risco à saúde pública. A transmissão de doenças dos animais para o homem pode se dar de forma direta, indireta ou por meio de vetores, que são seres vivos capazes de transferir um agente infeccioso de um hospedeiro a outro. Entre as infecções relatadas destaca-se a 
chikungunya, assumindo uma prevalência entre os moradores acometidos pela doença. Em torno de $70 \%$ dos entrevistados relataram que um ou mais membros de sua família tiveram esta doença, alguns inclusive também com a dengue e zica, as três transmitidas pelo mosquito Aedes Aegypti. Podemos cogitar que uma das consequências para esta situação é o aumento do número de criadouros potenciais do principal mosquito vetor (Aedes Aegypti) observados na comunidade, como uma grande quantidade de recipientes descartáveis, entre plásticos, latas, veículos automotores abandonados e pneus usados e outros materiais dispostos a céu aberto, cujo destino inadequado contribui para a proliferação do inseto transmissor da dengue.

A comunidade da Sombra dos Eucaliptos trata-se de uma área que foi ocupada por pessoas num processo de urbanização desordenada e apresenta deficiências de saneamento básico, habitação, assistência à saúde e de segurança pública, portanto as alterações no meio ambiente podem repercutir na saúde e qualidade de vida do ser humano.

O melhor método para se combater essa doença que acomete muitas pessoas na comunidade é evitando a procriação do mosquito, que ocorre em ambientes úmidos em água parada, seja ela limpa ou suja. A prevenção como estratégia para o enfrentamento da dengue, porém, é um desafio pois, vários são os pontos críticos no controle dessa doença: o biológico, o ambiental, o social e o institucional, todos eles observados no local da pesquisa.

Na comunidade Sombra dos Eucaliptos, na qual foi desenvolvida a pesquisa, foram observados aspectos relacionados à atuação do homem sobre o ambiente, quando foi possível constatar que algumas pessoas ainda deixam de exercer seu papel de cidadãs e acabam contribuindo para a criação de locais propícios para a proliferação do mosquito da dengue, e atribuem esse comportamento devido à falta, por exemplo, de contêineres para descartar o lixo, como mostra o relato de um morador "Eu acho que se tivesse onde as pessoas colocassem o lixo naqueles latões, talvez não tivesse tanto lixo jogado por aí, no meio da comunidade e nem as pessoas iam jogar mais no córrego" Outros entrevistados descreveram que a situação em que vivem é também devido à deficiente coleta do lixo, bem como o descaso do poder público para a comunidade.

Outro aspecto relevante no processo saúde/doença do indivíduo foi a falta de assistência primária à saúde voltada para a comunidade. Ao serem indagados sobre equipe de saúde presente na comunidade eles relatam: "Aqui ninguém da saúde vem visitar a gente, se a gente ficar doente que procure um lugar para atender senão a gente mor$r{ }^{\prime \prime}$. Assim sendo, ainda há muita invisibilidade em relação ao que acontece no dia a dia das favelas, sendo perceptível os limites e desafios das políticas públicas nesses locais.

Os programas de promoção da saúde relacionados com os problemas ambientais, entretanto, devem ser movimentos politicamente agressivos e emancipadores, socialmente justos, economicamente viáveis e ecologicamente prudentes, abordando a perspectiva de uma equidade social, política e econômica.

Diante do cenário identificado neste aglomerado subnormal, pôde-se constatar que a questão do manejo dos resíduos sólidos e líquidos está longe de se adequar aos parâmetros de conformidade com a legislação. Um dos principais problemas deste e de outros assentamentos precários é o fato de o escoamento de esgoto estar interligado à 
rede de drenagem de água pluvial, fazendo com que o destino final seja impactado por esta ação. Uma forma de minimizar o problema seria criar um sistema de esgotamento sanitário exclusivo para a comunidade da Sombra dos Eucaliptos. Este sistema pode ser interligado a outras tubulações de esgoto espalhadas pela cidade, de modo que sejam direcionadas para o devido tratamento na unidade de tratamento de esgoto localizada no Bairro do Trapiche da Barra. Uma alternativa, assim como é projetado em condomínios fechados, mediante parceria público/privada, poderia ser a de inserir uma Estação de Tratamento de Esgoto (ETE), de modo a tratar o esgoto, encaminhando o lodo para o aterro sanitário da capital e reaproveitando a água para serviços que não incluam a ingestão.

A partir de relatos dos moradores, contudo, sobretudo pela entrevista concedida por dois dos moradores mais antigos da comunidade, a criminalidade é o que torna o ambiente mais incômodo, provocando uma sensação de insegurança, motivo que fez com que muitas famílias saíssem da comunidade e motivo pelo qual a maioria dos moradores afirmam desejar sair.

\section{CONSIDERAÇÕES FINAIS}

Com base nos dados obtidos a partir da aplicação dos questionários é possível reconhecer que os problemas ambientais são os maiores causadores para a proliferação do mosquito Aedes Aegypti. Este fato reflete na frequência de indivíduos doentes, que, segundo relatos, perpassa praticamente todas as famílias ali residentes.

Os impactos na sociedade em relação ao manejo dos resíduos estão diretamente ligados aos reflexos na saúde e consequentemente à moradia adequada. É possível perceber, todavia, que a construção de habitações irregulares impacta também na precariedade da segurança, no acesso a emprego e educação e a outros tipos de assistência.

No que se refere ao reconhecimento do manejo inadequado do lixo, os moradores reconhecem que há uma falta de sensibilização e trabalho coletivo entre eles, para que o lixo seja acumulado para coleta, porém reconhecem também a ausência de assistência por parte do poder público, que segundo os moradores, deveria ao menos ceder lixeiras para incentivar o descarte correto. No que tange ao esgoto, tendo em vista que não há sistema de escoamento sanitário, pelo contrário, além desta favela há outras ligações de esgoto para a bacia, a maioria dos moradores não reconhece como um despejo incorreto, pois identifica que esta foi a forma imposta pelos governantes a partir do planejamento da cidade. A população do local reconhece que o excesso de esgoto, sobretudo no período chuvoso, contribui para o alagamento e na geração de transtorno no tráfego de veículos nas vias principais do entorno ao Polo Multissetorial, porém atestam que não há nada que possam fazer.

Em meio a estas percepções, o poder público apresentou efetividade inserindo a coleta semanal de resíduos e a ronda policial. Faz-se necessário, contudo, uma maior assistência ainda nestes pontos, mas sobretudo no acesso à educação e à saúde, pois os residentes da favela são submetidos a longas caminhadas para buscar assistência em bairros vizinhos. 
Em relação ao saneamento básico, problema da coletividade maceioense, é factível admitir que se faz necessária a construção de um sistema de esgotamento sanitário que desvincule a canalização de esgoto do sistema de águas pluviais a fim de proporcionar o funcionamento adequado da bacia de drenagem, não comprometendo a qualidade das águas subterrâneas.

Com base na percepção de valor dos residentes e da importância da preservação do meio ambiente nas comunidades de aglomerados subnormais, é correto afirmar que a população da comunidade da Sombra dos Eucaliptos, em sua maioria, espera que o poder público faça o "desfavelamento" e os abrigue em residências dentro dos padrões da construção civil. Enquanto isto, grande parte dos indivíduos ali inseridos seguem, cada um se comportando da maneira que melhor beneficie seu interesse particular.

Esta é uma realidade que perpassa outros aglomerados subnormais. Habitantes que admitem uma conduta que agride o meio ambiente, a saúde humana e a vida em sociedade e que atribui ao poder público a integralidade das condições de vida e moradia. Sabe-se, porém, que ações que proporcionem uma melhor aplicabilidade dos instrumentos da política urbana, que minimizem, planejem melhor e evitem desordenamento, precariedade, insalubridade e a procriação de pragas, são indispensáveis. Desse modo, faz-se necessário um trabalho em conjunto, cada um exercendo seu papel. Uma realidade que nem sempre funcionará de forma equilibrada, mas que deve ser aplicada continuamente.

Neste sentido, a pesquisa aqui apresentada empenhou-se em mostrar que adentrar a realidade das comunidades é necessário para se construir políticas públicas reconhecendo as histórias, relações afetivas e vínculos financeiros da população, além do seu histórico ambiental. Do mesmo modo, esta pesquisa revelou que aproximar os programas de saúde da comunidade, criar oficinas de educação ambiental, colocar à disposição as lixeiras tão cobradas pelos moradores também são formas de tornar efetivas as políticas de manejo, por meio dos próprios moradores, além de empenhar-se na fiscalização de empresas para a destinação correta de resíduos, na execução de obras de saneamento, garantindo que canalizações de água e esgoto não se conectem ao longo do processo, são algumas medidas primordiais do poder público para assegurar os direitos básicos da população. Tudo isto nos leva a concluir que neste momento, o foco nas melhores condições para aplicabilidade das políticas de manejo de resíduos, por meio dos profissionais que estarão na linha de frente, é o que irá conduzir à resolução destas questões urbanas que perpassam a saúde, o ambiente e a sociedade.

\section{REFERÊNCIAS}

ARRUDA, P. N.; LIMA, A. S. C.; SCALIZE, P. S. Gestão dos serviços públicos de água e esgoto operados por municípios em Goiás, GO, Brasil. Rev. Ambiente \& Água., Taubaté, v. 11, n. 2, p. 362-376, 2016.

BALTHAZAR, R. D. S. A permanência da autoconstrução: um estudo da sua prática no município de Vargem Grande Paulista. 2012. Dissertação (Mestrado) - Universidade de São Paulo, FAUUSP, São Paulo, 2012.

BARRETO, M. L.; TEIXEIRA, M. G. Dengue no Brasil: situação epidemiológica e contribuições para uma agenda de pesquisa. Revista Estud Av., São Paulo, 22(64), p. 53-72, dez. 2008.

BRASIL. Lei Federal no 12.305, de 2 de agosto de 2010. Institui a Política Nacional de Resíduos Sólidos e dá outras providências. Brasília: Diário Oficial da União, 2010.

BISPO, T. C.; LEVINO, N. de A. Impactos ambientais decorrentes do uso e ocupação desordenada do solo: um estudo da região da periferia de Maceió/Al. ENCONTRO NACIONAL DE ENGENHARIA DE PRODUÇÃO, 31., 2011, Belo Horizonte: Enegep, 2011. 
BUSS, P. M. Promoção da saúde e qualidade de vida. Revista Cienc. Saúde Colet., Rio de Janeiro, v. 5(2), p. 163-177, 2000.

CARDOSO, A. L. Assentamentos precários no Brasil: discutindo conceitos. Caracterização e tipologia de assentamentos precários: estudos de caso brasileiros. Editores Maria da Piedade Morais, Cleandro Krause e Vicente Correia Lima Neto. Brasília: Ipea, 2016.

DE ASSIS LIBÂNIO, C. O fim das favelas? Planejamento, participação e remoção de famílias em Belo Horizonte. São Paulo: Cadernos Metrópole, v. 18, n. 37, 2016.

Campo Grande, .

DENALDI, R.; FERRARA, L. N. A dimensão ambiental da urbanização em favelas. Revista Ambiente \& Sociedade, São Paulo, v. 21, 2018.

FRANCA, F. P. de O. et al. Correlação entre rendimento e geração de resíduos sólidos na região metropolitana de São Paulo. Revista Saúde Meio Ambiente, Campo Grande, v. 2, n. 1, p. 84-92, jan./jun. 2013.

GOUVEIA, N. Resíduos sólidos urbanos: impactos socioambientais e perspectiva de manejo sustentável com inclusão social. Revista Ciênc. Saúde Coletiva (on-line), v. 17, n. 6, p. 1.503-1.510, 2012. Disponível em: http://www.scielo.br/ scielo.php?script=sci_arttext\&pid=S1413-81232012000600014\&lng=en\&nrm=iso. Acesso em: 18 jul. 2019.

GUIMARÃES, A. J. A.; CARVALHO, D. F. de; SILVA, L. D. B. da. Saneamento e meio ambiente. 2007. Disponível em: http://www.ufrrj.br/institutos/it/deng/leonardo/downloads/APOSTILA/Apostila\%20I\%20179/ Cap\%203.pdf. Acesso em: 13 out. 2017.

IBGE. Instituto Brasileiro de Geografia e Estatística. Aglomerados subnormais levantamentos de informações territoriais: referências básicas. Rio de Janeiro: IBGE, 2010. Disponível em: www.ibge.gov.br. Acesso em: 2 jan. 2018.

IPEA. Instituto de Pesquisa Econômica Aplicada. Geopolítica das cidades: velhos desafios, novos problemas. Organizador Renato Balbim. Brasília: Ipea, 2016.

JACOBI, P. R.; BESEN, G. R. Gestão de resíduos sólidos em São Paulo: desafios da sustentabilidade. Revista Estudos Avançados, São Paulo, v. 25, n. 71, 2011.

LICCO, E. A.; DOWEL, F. M. Alagamentos, enchentes, enxurradas e inundações: digressões sobre seus impactos sócio econômicos e governança. Iniciação - Revista de Iniciação Científica, Tecnológica e Artística, São Paulo, v. 5, n. 3, 2015.

LIMA, A. D. Ecologia médica e uma visão holística no contexto das enfermidades humanas.: Revista Brasileira de Educação Médica, Rio de Janeiro, v. 38 (2), p. 165-172, 2014.

MOREIRA, Roberto. Economia política da sustentabilidade: uma perspectiva neomarxista. In: COSTA, L. F. C.; MOREIRA, R. J.; BRUNO, R. (orgs.). Mundo rural e tempo presente. Rio de Janeiro: Mauad, 1999.

NASCIMENTO, V. F.; SOBRAL, A. C.; ANDRADE, P. R. de; OMETTO, J. P. H. B. Evolução e desafios no gerenciamento dos resíduos sólidos urbanos no Brasil. Revista Ambiente \& Água, -Taubaté, v. 10, n. 4, p. 889902, 2015.

OLIVEIRA JÚNIOR, J. L. Tratamento descentralizado de águas residuárias domésticas: uma estratégia de inclusão social. In: LIRA, W. S.; CÂNDIDO, G. A. (org.). Gestão sustentável dos recursos naturais: uma abordagem participativa. Campina Grande: EDUEPB, 2013. p. 213-232.

ONU. Organização das Nações Unidas. Disponível em: https://treaties.un.org/pages/ViewDetails.aspx?src=IND\&mtdsg_no=IV-3\&chapter=4\&clang=_en. Acesso em: 3 set 2018a.

ONU. Organização das Nações Unidas. Disponível em: https://tbinternet.ohchr.org/_layouts/treatybodyexternal/Download.aspx?symbolno=E/C.12/BRA/CO/2\&Lang=En. Acesso em: 3 set. $2018 \mathrm{~b}$.

ONU. Organização das Nações Unidas. Disponível em: https://nacoesunidas.org/conheca-os-novos-17-objetivos-de-desenvolvimento-sustentavel-da-onu/. Acesso em: 3 set. 2018c.

SAWAYA, A. L.; ALBUQUeRQUE, M. P.; DOMENE, S. M. A. Violência em favelas e saúde. Revista Estudos Avançados, v. 32, n. 93, 2018.

SCHUELER, A. S.; KZURE, H.; RACCA, G. B. Como estão os resíduos urbanos nas favelas cariocas? URBE - Revista Brasileira de Gestão Urbana (Brazilian Journal of Urban Management), n. 10, v. 1, p. 213-230. 2018.

SILVA, K. C.; SAMMARCO, Y. M. Relação ser humano e natureza: um desafio ecológico e filosófico. Revista Monografias Ambientais, Santa Maria, v. 14, n. 2, maio/ago. 2015.

TAVARES, F. G. R. Resíduos sólidos domiciliares e seus impactos socioambientais na área urbana de Macapá-AP. 2014. 61 f. Trabalho de conclusão de curso (Bacharelado em Ciências Ambientais) - Fundação Universidade Federal do Amapá, Macapá/AP, 2014. 